\title{
Factors affecting the outcome in subdural empyema
}

\author{
HENK W MAUSER,* HANS C VAN HOUWELINGEN, $\dagger$ CEES A F TULLEKEN* \\ From the Department of Neurosurgery, * University Hospital Utrecht, and Department of Mathematical \\ Statistics, $\dagger$ University Utrecht, The Netherlands
}

SUMMARY The case reports of 102 patients with subdural empyema, diagnosed in the years 1935-83, were reviewed to determine the factors affecting the outcome. Statistical analysis (likelihood ratio tests with chi square approximation and logistic regression) showed that year of diagnosis $(p<0.01)$ and level of consciousness at the moment of diagnosis $(p<0.01)$ had a significant bearing on the chance to survive and that these same two factors (each factor $p<0.01$ ) and extent of subdural pus accumulation at the moment of diagnosis $(p<0.05)$ had a significant bearing on the chance of survival without severe disability. Among others the duration of the disease up to the moment of diagnosis and the mode of the first surgical procedure had no significant bearing on the outcome. These results together with those in the literature are discussed and it is concluded that diagnosis and treatment before the patient lapses into stupor or coma, increases the chance of survival and that with adequate management a mortality rate of $10 \%$ or lower is to be expected.

Subdural empyema is a rare intracranial infection with high mortality. A review in 1975 indicated a mortality rate of about $40 \% .^{1}$ In more recent series the mortality rate ranged from $12 \%$ to $29 \% .^{2-11}$ Bannister in 1981 stated that a mortality rate of about $10 \%$ is to be expected nowadays with early diagnosis and prompt treatment. He also stressed the importance of performing a craniotomy as the primary surgical procedure. ${ }^{4}$ To determine which factors affect the outcome 102 cases of subdural empyema, in which the diagnosis was established in the years $1935-83$, were reviewed.

\section{Patients and methods}

From the files of five neurosurgical centres in the Netherlands 102 patients were collected, in whom a subdural empyema was diagnosed between 1935 and 1983. In 97 cases the diagnosis was confirmed at operation. In four patients the diagnosis was made at necropsy and in one patient, who was treated non-surgically, CT confirmed the clinical diagnosis. The clinical findings of the patients have been reported in detail elsewhere. ${ }^{11}$

The outcome for each patient, mentioned in the clinical or outpatient chart, was graded according to a scale that was designed for this study (table 7). Grade A comprises patients who survived without or with a minor, not disabling, focal

Address for reprint requests: H W Mauser, Department of Neurosurgery, University Hospital, Catharijnesingel 101, 3511 GV Utrecht, The Netherlands.

Received 11 November 1986 and in revised form 26 February 1987. Accepted 28 February 1987 deficit. Grade B comprises patients with not disabling seizures during follow-up and without or with a minor, noto disabling, focal deficit. Grade $C$ comprises patients who survived severely disabled and Grade D patients who died.

Statistical analysis (likelihood ratio tests with chi square approximation and logistic regression) was performed to determine which factors up to the time of diagnosis had a significant influence on the outcome.

\section{Results}

In the years $1935-83$ a mean of 0.7 patients per annum in each centre was diagnosed. The incidence did not decrease in recent years (table 1). In table $2 \mathrm{a}$ and $2 \mathrm{~b}$ the aetiology and the age of the patients are presented. Paranasal sinus infections were the most common cause of subdural empyema (59\%). The category miscellaneous includes among others local osteomyelitis of the skull, infections of the lungs and skin (paronychium and panaritium) and three cases

Table 1 Number of patients in five subsequent periods and outcome of patients in each period $(n=102)$

\begin{tabular}{|c|c|c|c|c|}
\hline \multirow{2}{*}{$\begin{array}{l}\text { Year } \\
\text { of } \\
\text { diagnosis }\end{array}$} & \multirow{2}{*}{$\begin{array}{l}\text { Number } \\
\text { of } \\
\text { patients }\end{array}$} & \multicolumn{3}{|l|}{ Outcome } \\
\hline & & $\boldsymbol{A} / \boldsymbol{B}$ & $C$ & $D$ \\
\hline $\begin{array}{l}1935-50 \\
1951-60 \\
1961-70 \\
1971-80 \\
1981-83\end{array}$ & $\begin{array}{r}11 \\
26 \\
29 \\
28 \\
8\end{array}$ & $\begin{array}{c}5(46 \%) \\
12(46 \%) \\
19(66 \%) \\
18(64 \%) \\
8(100 \%)\end{array}$ & $\begin{array}{l}1(9 \%) \\
3(12 \%) \\
2(7 \%) \\
8(29 \%) \\
0(0 \%)\end{array}$ & $\begin{array}{c}5(46 \%) \\
11(42 \%) \\
8(28 \%) \\
2(7 \%) \\
0(0 \%)\end{array}$ \\
\hline
\end{tabular}


Table 2 Aetiology of subdural empyema and age of patients $(n=102)$

\begin{tabular}{|c|c|c|c|c|c|c|c|}
\hline $\begin{array}{l}\text { (a) } \\
\text { Aetiology }\end{array}$ & Sinusitis & Otitis & & Head injury & Operation & \multicolumn{2}{|c|}{ Miscellaneous } \\
\hline Number of patients & $60(59 \%)$ & $12(12 \%)$ & & $9(9 \%)$ & $6(6 \%)$ & & \\
\hline $\begin{array}{l}\text { (b) } \\
\text { Age (yr) }\end{array}$ & $0-9$ & $10-19$ & $20-29$ & $30-39$ & $40-49$ & $50-59$ & 60 years or older \\
\hline Number of patients & $10(10 \%)$ & $32(31 \%)$ & $28(28 \%)$ & $11(11 \%)$ & $9(9 \%)$ & $5(5 \%)$ & $7(7 \%)$ \\
\hline
\end{tabular}

Table 3 Symptoms and signs at time of diagnosis

\begin{tabular}{llllll}
\hline Headache & $92^{*}$ & $70(85 \%)$ & Disturbance of & $102^{*}$ & $86(84 \%)$ \\
Fever & $82^{*}$ & $79(96 \%)$ & consciouness & $102^{*}$ & $86(84 \%)$ \\
Severely ill & $59^{*}$ & $46(78 \%)$ & Seizures & $102^{*}$ & $55(54 \%)$ \\
Nuchal rigidity & $95^{*}$ & $78(82 \%)$ & Aphasia & $99^{*}$ & $25(25 \%)$ \\
\hline
\end{tabular}

*Number of patients about whom data were available.

with unknown aetiology. Subdural empyema was encountered at every age, but most patients were in the second $(32 \%)$ or third decade $(28 \%)$. Seventyeight per cent of the patients were male.

\section{Symptoms and signs}

A disturbance of consciousness was the presenting neurological sign in $55 \%$ of the patients, seizures in $16 \%$ and hemiparesis in $12 \%$. In $21 \%$ of the patients the diagnosis was established within 2 days of the first neurological sign, in $64 \%$ within 1 week and in $93 \%$ within 4 weeks. At the time of diagnosis $84 \%$ of the patients had a disturbed level of consciousness (table $3)$. Nearly half of the patients had a severe disturbance of consciousness (stuporose $22 \%$ and comatose $24 \%$ (table 4 )).

Hemiparesis was present in $84 \%$ of the patients at the time of diagnosis and seizures had occurred in

Table 4 Level of consciousness at time of diagnosis and outcome ( $n=98$; the four patients, who died before the diagnosis, are omitted)

\begin{tabular}{|c|c|c|c|c|}
\hline \multirow{2}{*}{$\begin{array}{l}\text { Level } \\
\text { of } \\
\text { consciousness }\end{array}$} & \multirow{2}{*}{$\begin{array}{l}\text { Number } \\
\text { of } \\
\text { patients }\end{array}$} & \multicolumn{3}{|l|}{ Outcome } \\
\hline & & $A / B$ & $C$ & $D$ \\
\hline $\begin{array}{l}\text { Normal } \\
\text { Somnolent* } \\
\text { Stuporose* } \\
\text { Comatose* }\end{array}$ & $\begin{array}{l}16 \\
36 \\
22 \\
24\end{array}$ & $\begin{array}{r}13(81 \%) \\
28(78 \%) \\
12(55 \%) \\
9(38 \%)\end{array}$ & $\begin{array}{l}2(13 \%) \\
3(8 \%) \\
4(18 \%) \\
5(21 \%)\end{array}$ & $\begin{array}{r}1(6 \%) \\
5(14 \%) \\
6(27 \%) \\
10(42 \%)\end{array}$ \\
\hline
\end{tabular}

*Somnolent: drowsy state from which the patient can be easily aroused by stimuli and the patient does not lapse immediately after ceasing stimulation.

*Stuporose: unresponsive state, from which the patient can be roused only by vigorous and repeated stimuli. As soon as the stimulation ceases the patient lapses into the unresponsive state.

*Comatose: unresponsive state, from which the patient cannot be aroused by any stimuli.
$54 \%$. Nuchal rigidity was found in $82 \%$ of the patients. Nearly all patients had a high temperature $(96 \%)$ and in about half of them the temperature was more than $40^{\circ} \mathrm{C}$. Most patients were severely ill (78\%) and complained of headache $(85 \%)$.

\section{Treatment}

Ninety-two patients were operated upon and treated with antibiotics; five patients were treated before the introduction of the antibiotics; one patient was treated nonsurgically. In four patients the subdural empyema was diagnosed at necropsy.

About the same number of patients were primarily treated with one or more burr holes (46 patients) as with a craniotomy (47 patients) and in three patients the mode of the first surgical procedure was not known (table 5). Fifty per cent of the patients primarily treated with burr holes, were operated upon again (61\% of them within 1 week of the first operation). Only $21 \%$ of the patients primarily treated with craniotomy, however, underwent a second operation $(80 \%$ of them more than 1 week after the first operation).

\section{Extension of the pus at the time of diagnosis}

In 79 patients $(78 \%)$ the subdural pus was located over one or two cerebral lobes and/or along the falx. The most common location was over the frontal lobe.

Table 5 Mode of the first surgical procedure $(n=97)$ and number of patients requiring a second operation

\begin{tabular}{lll}
\hline $\begin{array}{l}\text { Mode of first } \\
\text { surgical procedure }\end{array}$ & $\begin{array}{l}\text { Number of } \\
\text { patients }\end{array}$ & $\begin{array}{l}\text { Number of patients } \\
\text { requiring } 2 \text { nd operation }\end{array}$ \\
\hline Burr holes & 46 & $23(50 \%)$ \\
Craniotomy & 47 & $10(23 \%)$ \\
Unknown & 3 & $1(33 \%)$ \\
\hline
\end{tabular}


Table 6 Spread of subdural pus at time of diagnosis and outcome $(n=101)$

\begin{tabular}{lllll}
\hline $\begin{array}{l}\text { Spread } \\
\text { of } \\
\text { subdural pus }\end{array}$ & $\begin{array}{l}\text { Number } \\
\text { of } \\
\text { patients }\end{array}$ & Outcome & & \\
\cline { 5 - 5 } & $A / B$ & $C$ & $D$ \\
\hline $\begin{array}{c}\text { Over 1 or } 2 \\
\text { lobes and/or } \\
\text { along falx }\end{array}$ & 79 & $55(70 \%)$ & $8(10 \%)$ & $16(20 \%)$ \\
$\begin{array}{c}\text { Over } 1 \text { or } \\
\text { both } \\
\text { hemispheres }\end{array}$ & 22 & $7(32 \%)$ & $5(23 \%)$ & $10(46 \%)$ \\
\hline
\end{tabular}

Table 7 Scale according to which the outcome has been graded and the number of patients in each category $(n=102)$

\begin{tabular}{|c|c|c|}
\hline Grade A & Survival without or with a minor, & $40(39 \%)$ \\
\hline Grade B & $\begin{array}{l}\text { not disabiling, focal deficit } \\
\text { Survival with not disabling seizures } \\
\text { and without or with a minor, } \\
\text { not disabling, focal deficit }\end{array}$ & $22(22 \%)$ \\
\hline $\begin{array}{l}\text { Grade C } \\
\text { Grade D }\end{array}$ & $\begin{array}{l}\text { Survival with severe disablity } \\
\text { Death }\end{array}$ & $\begin{array}{l}14(14 \%) \\
26(26 \%)\end{array}$ \\
\hline
\end{tabular}

In 22 patients $(22 \%)$ the pus extended over the whole hemisphere ( 20 cases) or over both hemispheres (two cases) (table 6).

\section{Bacteriology}

The results of bacteriological investigations of the pus were known in 81 cases. The cultures were sterile in 37 patients $(46 \%)$. In the 44 other patients 49 microorganisms were cultured. Streptococci were found in 28 cases $(35 \%)$ (nine of these being anaerobic species) and Staphylococci in eight cases (10\%). Proteus mira- bilis was cultured in four cases, Streptococcus pneumoniae in three cases and Escherichia coli in two cases. The category miscellaneous includes a Bacteroides species, a Fusobacterium species, Haemophilus influenza and Candida albicans each in one case.

\section{Outcome}

The mean duration of the follow-up was 36.8 months with a range from 1 to 276 months. The outcome of each patient was graded according to a scale (table 7). In this table the number of patients in each grade is also indicated. Grade A comprises 40 patients $(39 \%)$. Nine of these patients had minor, not disabling, focal deficits. Twenty-two patients $(22 \%)$ had seizures during follow-up (Grade B). The seizures occurred sporadically and could be handled easily. Minor, not disabling, focal deficits were present in five of these 22 patients. Fourteen patients (14\%) survived severely disabled (Grade C). Seven of these 14 patients had seizures and in five of them the seizures were difficult to manage. Nine of these 14 patients had signs of an organic psycho-syndrome (in seven of them these signs were severe) and 11 patients had focal deficits (in eight of them these deficits were severe). The mortality rate (Grade D) in this series was $26 \%$.

\section{Factors affecting the outcome}

The bearing on the mortality (Grade D) and on severely disabled survival or mortality (Grade C or D) of 16 factors up to the time of diagnosis was statistically analysed (table 8).

The year of diagnosis and the level of consciousness

Table 8 Factors up to time of diagnosis that have been statistically analysed

\begin{tabular}{|c|c|c|c|c|}
\hline \multirow[b]{2}{*}{ Factor } & & \multirow[b]{2}{*}{ Number } & \multicolumn{2}{|c|}{ Likelihood ratio tests with $\chi^{2}$ approximation } \\
\hline & & & Grade D & Grade $C$ or $D$ \\
\hline $\begin{array}{l}1 \\
2 \\
3 \\
4 \\
5 \\
6 \\
7 \\
8 \\
9 \\
9 \\
10 \\
11 \\
12 \\
13 \\
14 \\
15 \\
16\end{array}$ & $\begin{array}{l}\text { Neurosurgical centre } \\
\text { Age } \\
\text { Year of diagnosis } \\
\text { Aetiology } \\
\text { Osteomyelitis of the skull } \\
\text { Period between the first symptom of the aetiology and } \\
\text { the time of the presenting of the first neurological sign } \\
\text { Period betwen the time of the first neurological sign } \\
\text { and the time of the first neurological examination } \\
\text { Consciousness at the time of the first } \\
\text { neurological examination } \\
\text { Period between the first neurological examination } \\
\text { and the time of diagnosis } \\
\text { Consciousness at the time of diagnosis } \\
\text { Seizures up to the time of diagnosis } \\
\text { Hemiparesis at the time of diagnosis } \\
\text { Herniation at the time of diagnosis } \\
\text { The mode of the first surgical procedure } \\
\text { Extension of the subdural pus at the time of diagnosis } \\
\text { Cultures of the subdural pus (positive or negative) }\end{array}$ & $\begin{array}{r}102 \\
102 \\
102 \\
102 \\
95 \\
93 \\
94 \\
101\end{array}$ & $\begin{array}{l}\text { NS } \\
\text { NS } \\
\text { p }<0.01 \\
\text { NS } \\
\text { NS } \\
\text { NS } \\
\text { NS } \\
\text { p }<0.05 \\
\text { NS } \\
\text { p }<0.01 \\
N S \\
\text { NS } \\
\text { NS } \\
\text { NS } \\
\text { NS } \\
\text { p }<0.05\end{array}$ & $\begin{array}{l}\text { NS } \\
\text { NS } \\
p<0.01 \\
\text { NS } \\
\text { NS } \\
\text { NS } \\
p<0.05 \\
p<0.05 \\
\text { NS } \\
p<0.01 \\
\text { NS } \\
\text { NS } \\
p<0.05 \\
\text { NS } \\
p<0.01 \\
\text { NS }\end{array}$ \\
\hline
\end{tabular}

In column 2 the number of patients is indicated. NS: not significant. 
at the time of diagnosis had a highly significant influence $(p<0.01)$ on mortality and survival with severe disability or mortality.

The mortality rate of $42 \%$ in the years $1951-60$ has decreased to $7 \%$ in the years $1971-80$ (table 1). This table also indicates that in the decade 1971-80 the rate of severely disabled patients has increased (1951-60: 12\%; 1971-80: 29\%). Further analysis revealed that the mortality rate of stuporose or comatose patients, in whom the subdural empyema was diagnosed within 1 week after the presenting neurological sign, has decreased. The severely disabled survival rate in this group of patients, however, increased (1951-60: 10\%; 1971-80: 51\%). This suggests that in recent years patients with an acute deteriorating illness had a lower mortality rate than in earlier years, but also that this lower mortality rate was connected with a higher rate of severely disabled survival.

The level of consciousness at the time of diagnosis also had a highly significant relation with the outcome. The chance of survival without severe disability decreased from $81 \%$ in patients with no impairment of consciousness to $38 \%$ in patients who were comatose at the time of the diagnosis (table 4).

The extent of the subdural pus accumulation, as determined at the time of diagnosis, had a highly significant bearing $(p<0.01)$ on the combined rate of mortality and severely disabled survival. Logistic regression revealed that this influence could partly be explained by the dependence between the extent of the subdural pus accumulation and the level of consciousness at the time of diagnosis. However, there was still a significant influence $(p<0.05)$ after correcting for year of diagnosis and level of consciousness at the time of diagnosis. The patients with a diffuse subdural pus accumulation (over a whole hemisphere or over both hemispheres) had a lower rate of survival without severe disability than the patients with a localised accumulation (over one or two cerebral lobes and/or along the falx) (table 6). The period between the time the first neurological symptom presented and the time of the first neurological examination, the level of consciousness at the time of the first neurological examination, signs of herniation at the time of diagnosis and the results of the cultures of the subdural pus had also a significant bearing ( $p<0.05)$ on the outcome (table 8). Logistic regression, however, revealed that the influence of these four factors was not independent.

The mode of the first neurosurgical procedure had no significant bearing on the outcome. Further analysis, relating the outcome with the level of consciousness at the time of diagnosis and the mode of the first surgical procedure (table 9) suggested that primary treatment with craniotomy in patients with a normal or a slightly disturbed level of consciousness at the time of diagnosis resulted in a slightly better outcome than primary treatment with burr holes. However, stuporose or comatose patients primarily treated with a craniotomy had a slightly worse outcome than patients primarily treated with burr holes.

Summarising, these results indicate that, in retrospect, year of diagnosis and level of consciousness at the time of diagnosis suffice to make a prognosis about the chance of survival and that these same two factors and extent of subdural pus accumulation at the time of diagnosis suffice to make a prognosis about the chance of survival without severe disability.

\section{Discussion}

Delay in diagnosis and treatment (prompt surgical treatment and antibiotics) has always been considered to be the main cause of the high mortality rate in patients with subdural empyema. ${ }^{14512}$ Recently it has been stressed that the type of the first surgical procedure has also an important bearing on the outcome. ${ }^{4}$ According to this study the mortality rate of the patients, primarily treated with burr holes, is about three times higher than in the group of patients primarily treated with craniotomy. In the current series year of diagnosis and level of consciousness at the time of diagnosis had a significant bearing on the chance of survival and these two factors and extent of subdural pus accumulation had a significant bearing on the chance of survival without severe disability.

Age of the patient and aetiology of the subdural empyema had no significant bearing on the outcome in this series. Other series, however, indicated a better

Table 9 The outcome related with level of consciousness at time of diagnosis and mode of the first surgical procedure $(n=93)$

\begin{tabular}{|c|c|c|c|c|c|}
\hline \multirow{2}{*}{$\begin{array}{l}\text { Level of } \\
\text { consciousness }\end{array}$} & \multirow{2}{*}{$\begin{array}{l}\text { Mode of } \\
\text { operation }\end{array}$} & \multirow{2}{*}{$\begin{array}{l}\text { Number of } \\
\text { patients }\end{array}$} & \multicolumn{3}{|l|}{ Outcome } \\
\hline & & & $A / B$ & $C$ & $D$ \\
\hline $\begin{array}{l}\text { Normal or } \\
\text { somnolent } \\
\text { Stuporose or } \\
\text { comatose }\end{array}$ & $\begin{array}{l}\text { Burr holes } \\
\text { Craniotomy } \\
\text { Burr holes } \\
\text { Craniotomy }\end{array}$ & $\begin{array}{l}23 \\
26 \\
23 \\
21\end{array}$ & $\begin{array}{l}16(70 \%) \\
22(85 \%) \\
12(52 \%) \\
8(38 \%)\end{array}$ & $\begin{array}{l}3(13 \%) \\
2(8 \%) \\
4(17 \%) \\
5(24 \%)\end{array}$ & $\begin{array}{l}4(17 \%) \\
2(8 \%) \\
7(30 \%) \\
8(38 \%)\end{array}$ \\
\hline
\end{tabular}


outcome for patients 10-20 years old and for patients with a sinusitis-induced subdural empyema. ${ }^{45}$ The reason for these discrepancies is not known.

Although most authors agree that a delay in diagnosis and treatment increase the mortality rate, ${ }^{1-578}$ the time elapsed between the first neurological sign and the time of diagnosis had no significant bearing on the outcome in the current series. This finding can be explained by assuming that the clinical picture can run an acute or subacute course. Others have also mentioned this difference in the clinical course and suggested also that the patients with a more protracted course had a better outcome than the patients with an acute course. ${ }^{51112}$ It is conceivable that in the group with a protracted course the number of patients with a severe disturbance of consciousness at the time of diagnosis is lower than in the group with an acute course. This will result in a lower mortality rate.

In the current investigation patients with a severe disturbance of consciousness at the time of diagnosis had a significantly worse outcome than the patients with a normal or slightly disturbed level of consciousness. The chance of survival without severe disability decreased from $81 \%$ in patients without any disturbance of consciousness to $38 \%$ in the group of patients who were comatose at the time of diagnosis and the mortality rate increased from $6 \%$ to $42 \%$. Comparable figures have been found by others. ${ }^{4}$ These findings stress the importance of diagnosing a subdural empyema before the patient lapses into stupor or coma. Also it can be concluded that the number of patients with a severe disturbance of consciousness has to be known in order to allow a reliable comparison between different series.

The mode of the primary surgical procedure had no bearing on the outcome in the current series, although a second operation was more often performed in the group primarily treated with burr holes than in the group primarily treated with a craniotomy. This finding is different from the conclusion of a recent study, comprising a series of 66 patients and a review of the literature. ${ }^{4}$ In this study it was concluded that the primary performance of burr holes has a negative bearing on the outcome. It has also been suggested that burr holes contribute to a higher rate of severely disabled survival. ${ }^{6}$ The explanation for these different conclusions is not clear, but some points can be made.

In the first place the lower number of patients with a severe disturbance of consciousness $(21 \%)^{4}$ compared with the number in the current series $(47 \%)$ may partly explain this discrepancy. The results of the current investigation suggest that the preferred mode of operation depends on the level of consciousness at the time of diagnosis (no or a slight disturbance of consciousness: craniotomy; severe disturbance of consciousness: burr holes). In the past this preference for burr holes as the primary procedure in severely ill patients has also been noticed. ${ }^{1314}$

A second point to be made is the composition of the subdural pus. In the acute stage the pus is fluid and forms a thin, extended layer in the subdural space, whereas in the chronic stage the pus is encapsulated in pockets. ${ }^{1115}$ In the latter case craniotomy is probably to be preferred because multiple pockets of pus are more difficult to remove with burr holes. ${ }^{1216}$ In acutely ill patients, however, the thin layer of fluid pus can probably be removed as effectively with a craniotomy as with well-placed burr-holes (guided by aetiology, clinical picture and results of CT scanning). It is not conceivable that an extensive accumulation of subdural pus can be completely removed with either method. Leaving behind small accumulations of subdural pus is probably not hazardous for the patient because with adequate antibiotic treatment small accumulations of pus can disappear without further operation. ${ }^{1217}$ This has recently also been documented in a few nonsurgically treated patients. ${ }^{18} 19$

In the group of patients with pus over the whole hemisphere or over both hemispheres at the time of diagnosis the chance of survival without severe disability was significantly decreased compared with the group with a localised accumulation of pus. The literature contains no further information about this point, although it has been noticed that bilateral spread is common in severely ill patients. ${ }^{12}$ The worse outcome with an extensive accumulation of pus may be explained by assuming that this large extent reflects a wide spread pachymeningitis interna and consequently an extensive involvement of the adjacent cortex.

In recent years the mortality rate of subdural empyema has decreased. In a review in 1975 a mortality rate of about $40 \%$ was mentioned, ${ }^{1}$ but in series after 1980 the mortality rate ranged from $12-29 \% .^{2-11}$ It has been stated that a mortality rate of about $10 \%$ is to be expected nowadays. ${ }^{4}$ The current investigation confirms this statement with a mortality rate of $7 \%$ in the years 1971-80. It was also noted, however, in this study, that the severely disabled survival rate has increased in recent years, especially in patients with an acutely deteriorating illness. This increase has not been mentioned by others. ${ }^{46}$

The cause of the decreased mortality rate is not clear. It has been argued that a radical removal of pus by craniotomy at the earliest possible stage would be the most important step decreasing the mortality rate. ${ }^{4}$ However, this point of view is not supported by the results of the current investigation. Other factors must be responsible for this decrease. Among unrecognised factors, the introduction of CT, facili- 
tating the diagnosis and management of subdural empyema ${ }^{510}$ and the recognition of anaerobes as a common causative microorganism in subdural empyema ${ }^{20}$ may have contributed to this decrease. In cerebral abscesses the recognition of anaerobes has led to a decrease of the mortality rate. ${ }^{2122}$

\section{Conclusions}

The level of consciousness and the extent of the subdural pus at the time of diagnosis have a significant bearing on the outcome. Diagnosis and treatment, before the patient lapses into stupor or coma, will increase the chance of survival. In patients with no or slight impairment of consciousness, craniotomy may be the preferred mode of operation, whereas in stuporose or comatose patients multiple burr holes may be the preferred mode of operation. Besides operation antibiotic treatment, directed also against anaerobes, has to be started immediately. This management will probably result in a mortality rate of about $10 \%$ or even lower, but may also result in a higher rate of severely disabled survival in patients with an acute deteriorating illness.

\section{References}

1 Kaufman DM, Miller MH, Steigbigel NH. Subdural empyema: analysis of 17 recent cases and review of the literature. Medicine 1975;54:485-98.

2 Borzone M, Capuzzo T, Rivano C, Tortori-Donati P. Subdural empyema: fourteen cases surgically treated. Surg Neurol 1980;13:449-52.

3 Renaudin JW, Frazee J. Subdural empyema-importance of early diagnosis. Neurosurgery 1980;7:477-9.

4 Bannister G, Williams B, Smith S. Treatment of subdural empyema. J Neurosurg 1981;55:82-8.

5 Williams B. Subdural empyema. In: Krayenbühl H, ed. Advances and Technical Standards in Neurosurgery, vol 9. Wien/New York: Springer Verlag, 1982:133-70.

6 Cowie R, Williams B. Late seizures and morbidity after subdural empyema. J Neurosurg 1983;58:569-73.

7 Kaufman DM, Litman N, Miller MH. Sinusitis: induced subdural empyema. Neurology 1983;33:123-32.

8 Smith HP, Hendrick EB. Subdural empyema and epidural abscess in children. $J$ Neurosurg 1983;58:392-7.

9 Calliauw L, Praetere P de, Verbeke L. Postoperative epilepsy in subdural suppurations. Acta Neurochir 1984;71:217-23.

10 Zimmerman RD, Leeds NE, Danziger A. Subdural empyema: CT findings. Radiology 1984;150:417-22.

11 Mauser HW. Thesis: het subdurale empyeem (with a summary in English), 1986.

12 Hitchcock E, Andreadis A. Subdural empyema; a review of 29 cases. J Neurol Neurosurg Psychiatry 1964;27:422-34.

13 Wood PH. Diffuse subdural suppuration. J Laryngol Otol 1952;66:496-515.

14 List CF. Diagnosis and treatment of acute subdural empyema. Neurology 1955;5:663-70.

15 Courville CB. Subdural empyema secondary to purulent frontal sinusitis (a clinicopathological study of forty-two cases verified at autopsy). Arch Otolaryngol 1944;39:211-30.

16 Bhandari YS, Sarkari NBS. Subdural empyema (a review of 37 cases). J Neurosurg 1970;32:35-9.

17 Schiller F, Cairns H, Russel DS. The treatment of purulent pachymeningitis and subdural suppuration with special reference to penicillin. J Neurol Neurosurg Psychiatry 1948; 11:143-82.

18 Rosazza A, Tribolet N de, Deonna T. Nonsurgical treatment of interhemispheric subdural empyemas. Helv Paed Acta 1979;34:577-81.

19 Mauser HW, Ravijst RAP, Elderson A, Gijn J van, Tulleken CAF. Nonsurgical treatment of subdural empyema. $J$ Neurosurg 1985;63:128-30.

20 Yoshikawa TT, Chow AW, Guze LB. Role of anaerobic bacteria in subdural empyema (report of 4 cases and review of 327 cases from the English literature). Am J Med 1975;58:99-104.

21 Garfield J. Brain abscesses and focal suppurative infections. In: Vinken PJ, Bruyn GW, eds. Handbook of Clinical Neurology, vol 33: Infections of the Nervous System. Part I. Amsterdam: North Holland Publishing Company, 1978;chapter 9:107-47.

22 Garvey G. Current concepts of bacterial infections of the central nervous system (bacterial meningitis and bacterial brain abscess). J Neurosurg 1983;59:735-44. 